\begin{tabular}{|l|l|}
\hline $\begin{array}{l}\text { Postprint } \\
\text { Version } \\
\text { Journal website }\end{array}$ & $\begin{array}{l}1.0 \\
\text { http://onlinelibrary.wiley.com/doi/10.1111/j.1365- } \\
\text { 2753.2010.01544.x/abstract;jsessionid=15C9D1B87265F23BEEB9250EDF7EF8 } \\
\text { ED.d02t02 }\end{array}$ \\
\hline Pubmed link & http://www.ncbi.nlm.nih.gov/pubmed/20973871 \\
\hline DOI & $\begin{array}{l}\text { 10.1111/j.1365-2753.2010.01544.x } \\
\text { This is a NIVEL certified Post Print, more info at http://www.nivel.eu }\end{array}$ \\
\hline
\end{tabular}

\title{
Possible solutions for barriers in incident reporting by residents
}

KARTINIE MARTOWIRONO MSC ${ }^{1, *}$, JOSÉ D. JANSMA MSC², SCHELTUS J. VAN LUIJK MD $\mathrm{PHD}^{3}$, CORDULA WAGNER MA PHD ${ }^{4}$, A. BART BIJNEN MD PHD

${ }^{1}$ Junior Researcher, Foreest Medical School, Medical Center Alkmaar, Alkmaar, The Netherlands

2 Junior Researcher, Foreest Medical School, Medical Center Alkmaar, Alkmaar, The Netherlands, and Junior Researcher, Department of Public and Occupational Health, EMGO Institute for Health and Care Research (EMGO+), VU University Medical Center, Amsterdam, The Netherlands

${ }^{3}$ Associate Professor of Medical Education, VU University Medical Center, Institute for Education and Training, Amsterdam, The Netherlands

${ }^{4}$ Professor of Patient Safety, EMGO Institute for Health and Care Research (EMGO+), VU University Medical Center, Amsterdam, The Netherlands and Professor of Patient Safety, NIVEL, The Netherlands Institute for Health Services Research, Utrecht, The Netherlands

${ }^{5}$ Professor of Surgery, Foreest Medical School, Medical Center Alkmaar, Alkmaar, The Netherlands and Professor of Surgery, VU University Medical Center, Institute for Education and Training, Amsterdam, The Netherlands

\begin{abstract}
Rationale, aims and objectives Incident reporting can contribute to safer health care. Since the rate of reporting by residents is low, it is useful to investigate which barriers exist and how these can be solved.

Methods Data were collected in a large teaching hospital in the Netherlands. The hospital uses a confidential, voluntary and web-based incident reporting system. Residents working in the hospital participated in focus group discussions to explore barriers and possible solutions. A grounded theory approach was used to analyse the transcribed discussions.

Results In each focus group six to eight residents participated, resulting in a total number of 22 participants. After three focus group discussions, information saturation had been reached. Residents do not report all incidents because of a negative attitude towards incident reporting, because they experience a nonstimulating culture and because of a lack of perceived ability to report. Residents suggest several solutions to solve the barriers: providing the possibility to report anonymously, providing feedback, creating an incident reporting culture, simplifying the procedure, clarifying what and how to report, and exciting residents to report.
\end{abstract}


Conclusions Residents have useful suggestions to resolve the barriers that prevent them from reporting incidents. They include solutions that influence attitude, culture and perceived ability. These suggestions should be considered when making an effort to improve incident reporting by residents.

\section{INTRODUCTION}

The analysis of incidents collected through reporting systems can provide knowledge about the nature and causes of these incidents ${ }^{[1]}$. This knowledge can be used to develop initiatives to prevent incidents from happening again. Residents commonly encounter incidents ${ }^{[2,3]}$. Unfortunately, underreporting is a significant problem, undermining the ability to improve patient safety ${ }^{[4-6]}$.

In a large teaching hospital in the Netherlands, in 2007/2008, a study was conducted to explore the effectiveness of a 2-day patient safety curriculum on the attitudes, intentions and behaviour of residents towards voluntary incident reporting. It concluded that patient safety education can have long-term positive effects on the incident reporting attitudes and behaviour of residents. However, the study revealed an unclarified inconsistency between individuals' intentions to report incidents and actual changes in incident reporting behaviour. Further research was recommended to gain insight in the existing barriers that hinder reporting of incidents and to learn how these barriers can be overcome (J. D. Jansma, C. Wagner, R. W. Ten Kate, A, B. Bijnen, unpublished data). This study carries on from the patient safety curriculum study and is conducted in the same hospital. It not only explores the barriers that residents experience towards incident reporting, but also focuses on the solutions that residents provide for solving them, since this may result in improvements of the incident reporting system that actually fit the residents' needs.

The available information on barriers to incident reporting by residents is mainly based on surveys. They include lack of feedback, lack of time, extra paper work and concerns about career and personal reputation ${ }^{[6,7]}$. To our knowledge, there is no qualitative information available about solutions suggested by residents to overcome the barriers.

This study provides information on barriers and solutions based on focus group discussions rather than on surveys thereby using group processes to help people to explore and clarify their views which enables dimensions of understanding in the views of participants that other methods cannot reach ${ }^{[8-10]}$. This enhanced understanding is useful when efforts are made to optimize the incident reporting system. By conducting this study, we sought to answer the following research question: which barriers to incident reporting do residents experience and how can these be tackled?

\section{METHODS}

\section{Setting}

Data were collected in August and October 2008 in a large teaching hospital in the Netherlands which has a total capacity of 706 beds. In this period 159 residents worked in the hospital. The hospital uses a confidential, voluntary and web-based incident reporting system. It is possible to report an incident that involves the resident himself as well as to report an incident that involves a colleague.

\section{Participants}

All residents working in the hospital received an invitation by e-mail to participate in a focus group session. To increase the number of respondents, focus groups were held late afternoon in the hospital while a simple meal was provided. Afterwards participants received a gift coupon of $€ 25$. 
Martowirono, K., Jansma, J.D., Luijk, S.J. van, Wagner, C., Bijnen, A.B. Possible solutions for barriers in incident reporting by residents. Journal of Evaluation in Clinical Practice: 2010

\section{Data collection}

Data were collected through focus group discussions. Focus groups are a form of group interview that uses the communication between participants in order to generate data. The interaction among participants can provide valuable information when exploring complex behaviour and underlying motivations ${ }^{[9,10]}$.

Focus group discussions were set up until information saturation was reached. A skilled moderator facilitated the focus groups using a topic guide ${ }^{\text {Table } 1}$ ). The guide was developed by studying the literature. The first version was reviewed by an expert panel and revised before use. The opening questions only served as an introduction, focusing the participants on the issues that were being discussed. Preceding the actual focus group discussions, the conditions for an open discussion were optimized by putting emphasis on the fact that the moderator was not associated to the hospital and by underlining the confidentiality of the collected data. An incident was defined as an unforeseen event while providing care that caused, could have caused, or can still cause injury to the patient ${ }^{[11]}$. During the focus groups two of the authors (KM, JDJ) observed and took notes. After the focus group discussions the participants received a summary of the results to comment upon.

\section{[TABLE 1]}

\section{Data analysis}

The focus groups were recorded and transcribed verbatim. The transcriptions were entered into qualitative data analysis software (Atlas-ti, The Knowledge Workbench) ${ }^{[12]}$. The data transcriptions and observation notes - were then inductively analysed following the three steps of coding: open coding, axial coding and selective coding ${ }^{[13]}$. During the process the authors KM and JDJ discussed any difficulties or uncertainties until agreement was reached. A summary of the results was sent to the participants by e-mail for feedback.

\section{RESULTS}

\section{Participants and focus groups}

Of the 159 residents who received an invitation, 22 (13.8\%) participated in a focus group discussion. Not all disciplines were equally represented. Several cancelations were received. The reasons most mentioned for not participating in a focus group discussion were: being on duty; or vacation. Three focus groups were set up. Each group consisted of six to eight residents. Table 2 summarizes the characteristics of the focus group participants. After three focus groups, information saturation had been reached. The final questions did not result in any major changes of the topic guide. Eight participants responded to the e-mail with the summary of results. Their comments did not lead to any major changes.

\section{Barrier 1: a negative attitude}

I: 'Sometimes you know that a certain incident has already been reported, but no one acted upon it. Then why bother to report that kind of incident again? Last Friday an epidural and an intravenous infuse were switched. That is tedious, but it did not happen for the first time and the connections are still the same. Who will start to change that?'

II: 'Yeah, and probably it is still the same nurse who commits that mistake.'

Incident reporting is negatively valued by residents. Firstly, reporting an incident costs time and is perceived as another administrative act they have to carry out, while they prefer to spend their time on relevant medical activities for patients. Secondly, residents do not always agree with the definition of an incident. Instead of reporting all unforeseen events that caused, could have caused, or can still cause injury to a patient, they assess the usefulness of reporting a certain incident by evaluating the incident characteristics. For example, an incident can be perceived as not useful to report, because it has no major patient consequences. Several incident characteristics that are evaluated are described in ${ }^{\text {Table } 3}$. 
Martowirono, K., Jansma, J.D., Luijk, S.J. van, Wagner, C., Bijnen, A.B. Possible solutions for barriers in incident reporting by residents. Journal of Evaluation in Clinical Practice: 2010

\section{[TABLE 2]}

\section{[TABLE 3]}

Furthermore, the lack of feedback on a report and the absence of visible system changes strengthens the reservations to report. Besides, reporting an incident can be perceived as disloyal to colleagues as well as not one's responsibility. Finally, residents do not report all incidents because of the perceived negative consequences for themselves, such as legal liability and unpleasant working conditions.

\section{Barrier 2: a non-stimulating culture}

I: 'It is kind of frowned upon. I'll report this! It's often used as a threat, which makes reporting an incident difficult.'

Residents mentioned that superiors do not encourage them to report incidents. Next, incident reporting is considered to be emotionally charged. A vicious circle exists and is maintained: if few incidents are reported, incident reporting will remain emotionally charged. The situation differs between wards.

\section{Barrier 3: a lack of perceived ability}

I: 'I remember that it takes 15 minutes to make a report. The other day, I wanted to report something. It took quite some time to find the form I needed.'

II: 'Yeah, if you don't know where to find it, it can certainly take some time.'

I: 'Exactly, that should be easier. I had to fill out to much forms. So I quit. That was the reason. It took too much time.'

A few residents stated that they do not report incidents, because they simply do not think of it. Furthermore, some residents mentioned that they do not know what and how to report.

Also, the procedure used is perceived as not user-friendly. This barrier was most frequently mentioned. The web-based system is too complicated - for example, one has to fill out all fields of the web form before the form can be submitted, even if one does not have an answer - and takes too much time which residents do not have because of their busy working schedules.

\section{Residents' suggestions for improving incident reporting}

I: 'It would be nice when, just like the ICT-helpdesk, you can make a phone call to report. You talk to someone and give the essentials. If necessary, they can call back later.'

II: 'Or send an e-mail.'

I: 'I know for sure that the amount of reports will increase.'

Specific suggestions to solve the barriers they experience are shown in ${ }^{\text {Table } 4}$. It should be mentioned that not all residents agreed on anonymous incident reporting. The advantage mentioned was that in this case incident reporting cannot lead to any negative consequences for the residents themselves. Some objections that were mentioned were the fact that in practice it is always possible to find out who was involved in the incident and that interpreting anonymous reports can be difficult. In general, the residents stated that they would like to be consulted more often when new policies that affect residents are prepared because this could lead to policies that actually fit the residents.

\section{Getting round barriers in practice}

Some residents mentioned that they already found a way to get round the perceived barriers in practice, for example asking a nurse to make a report or discussing an incident with the colleagues involved. They stated that this is more effective, less time-consuming and less disloyal to colleagues than making a report. After discussing an incident, reporting is frequently considered to be duplicitous. 
Martowirono, K., Jansma, J.D., Luijk, S.J. van, Wagner, C., Bijnen, A.B. Possible solutions for barriers in incident reporting by residents. Journal of Evaluation in Clinical Practice: 2010

\section{DISCUSSION}

This study explored the barriers that residents experience to reporting incidents and how these barriers can be solved according to the residents. A negative attitude, a non-stimulating culture and a lack of perceived ability prevent residents from reporting. Residents suggested several practicable solutions to solve the barriers: providing the possibility to report anonymously, providing feedback, creating an incident reporting culture, simplifying the procedure, clarifying what and how to report and exciting residents to report.

\section{[TABLE 4]}

\section{[FIGURE 1]}

\section{The theory of planned behaviour}

The barriers that are found can be categorized using the theory of planned behaviour (TPB). The TPB is a widely used social psychological model focusing on the relationship between attitude, subjective norm, behavioural control, intention and behaviour. In short, the theory considers intention to be the immediate antecedent of behaviour. The intention is based on attitude, subjective norm and behavioural control ${ }^{[14]}$. Previously it was suggested that the TPB has relevance for studying the behaviour of health care providers ${ }^{[15]}$. Figure 1 shows a simplified TPB model and the relation to the barriers that are found in this study.

\section{Practical implications}

For as far as we know no other qualitative study on barriers to incident reporting by residents was ever conducted. Although other studies discovered similar barriers based on surveys, the data collected through focus group discussions provides enhanced information that can be very useful. For example, we discovered that the barrier negative attitude consists of many components, which all should be considered in attempts to improve incident reporting by residents.

Our findings showed that in practice residents find ways to get round barriers, for example by discussing incidents with colleagues. This was also demonstrated in previous studies ${ }^{[5,16]}$. It shows that it is important to underline the significance of formal incident reporting.

Several solutions that were mentioned during the focus group discussions are studied before in quantitative studies. For example, some residents suggested that it should be possible to make a report anonymously. Sharma et al. demonstrated that $44 \%$ of the surgical trainees participating in their study would report more if the system was anonymous ${ }^{[6]}$. Another solution that the residents provided was to simplify the procedure by introducing a card system instead of a web-based reporting system. Schuerer et al. conducted a study on the introduction of a new card system in a surgical intensive care unit. This card system replaced an underused online system. The study concluded that a card reporting system, combined with appropriate education, improved overall reporting, especially among doctor providers ${ }^{[17]}$. By contrast, Fukada et al. in their study on the impact of system-level activities and reporting design on the number of incident reports in teaching hospitals in Japan demonstrated that online reporting can lead to a $26 \%$ increase in doctors' reports. They also demonstrated, in accordance to our findings, that educational activities and a reporting system that consumes less time may improve incident reporting ${ }^{[18]}$. We explored solutions that residents themselves suggested to improve incident reporting. Residents perceived the focus group discussions as pleasant and valuable, since they felt they finally had the chance to be involved in policies regarding patient safety in a way that is bottom-up instead of topdown. When making efforts to improve incident reporting by residents these suggestions mentioned by the residents themselves should especially be taken into account.

The barriers found in this study can be categorized using the TPB. This is useful since the several practicable manuals for constructing TPB questionnaires and interventions can be used when considering further research based on our findings ${ }^{[19-21]}$. 
Martowirono, K., Jansma, J.D., Luijk, S.J. van, Wagner, C., Bijnen, A.B. Possible solutions for barriers in incident reporting by residents. Journal of Evaluation in Clinical Practice: 2010

\section{Limitations}

This study has several limitations.

Focus groups contain the risk of social desirability. The possibility exists that some respondents gave answers that were perceived to be more socially acceptable by the group. However, to prevent this from happening the preconditions for an open discussion were optimized putting emphasis on the fact that the moderator was not associated to the hospital and by underlining the confidentiality of the conversations.

This study was conducted in one large teaching hospital in the Netherlands. This hospital uses a web-based, confidential, voluntary reporting system. If questions may rise about the generalizability to hospitals where for example different reporting system are used, quantitative research based on the current findings or a study with a similar approach to this study can be conducted to uncover barriers and solutions in another context.

\section{Conclusion}

Residents have useful suggestions to resolve the barriers that prevent them from reporting incidents. They include solutions that influence attitude, culture and perceived ability. These suggestions should be considered when making an effort to improve incident reporting by residents. Quantitative research based on the current findings or a study with a similar approach to this study can be conducted to uncover barriers and solutions specific to another hospital.

\section{ACKNOWLEDGEMENTS}

$\mathrm{KM}$ and JDJ set up the research, collected the data, performed the data analysis and drafted the manuscript with intense assistance of and supervision by SJVL, CW and ABB. SJVL. also acted as moderator during the focus group discussions.

\section{REFERENCES}

1 Barach, P. \& Small, S. D. (2000) Reporting and preventing medical mishaps: lessons from non-medical near miss reporting system. British Medical Journal, 320, 759-763.

2 Singh, H., Thomas, E. J., Petersen, L. A. \& Studdert, D. M. (2007) Medical errors involving trainees. Archives of Internal Medicine, 167, 2030-2036.

3 Jagsi, R., Kitch, B. T., Weinstein, D. F., Campbell, E. G., Hutter, M. \& Weissman, J. S. (2005) Residents report on adverse events and their causes. Archives of Internal Medicine, $165,2607-2613$.

4 Kaldjian, L. C., Jones, E. W., Wu, B. J., Forman-Hoffman, V. L., Levi, B. H. \& Rosenthal, G. E. (2008) Reporting medical errors to improve patient safety. Archives of Internal Medicine, 168, 40-46.

5 Logio, L. S. \& Ramanujam, R. (2010) Medical trainees' formal and informal incident reporting across a five-hospital academic medical center. The Joint Commission Journal on Quality and Patient Safety, 36, 36-42.

6 Sharma, A., Jain, P., Parmar, B., Muzaffar, J. \& Monson, J. R. T. (2008) Incident reporting in surgical trainees - revisited. Journal of Patient Safety, 4, 1-4.

7 Coyle, Y. M., Mercer, S. Q., Murphy-Cullen, C. L., Schneider, G. W. \& Hynan, L. S. (2005) Effectiveness of a graduate medical education program for improving medical event reporting attitude and behavior. Quality and Safety in Health Care, 14, 383-388.

8 Pope, C. \& Mays, N. (1995) Reaching the parts other methods cannot reach: an introduction to qualitative methods in health and health services research. British Medical Journal, 311, 42-55.

9 Kitzinger, J. (1995) Introducing focus groups. British Medical Journal, 311, 299-302.

10 Morgan, D. L. \& Krueger, R. A. (1997) The Focus Group Kit, Volume 1 The Focus Group Guidebook. London: Sage Publications.

11 Wagner, C. \& Van der Wal, G. (2005) Voor een goed begrip [For good understanding]. Medisch Contact, 47, 1888-1891. 
Martowirono, K., Jansma, J.D., Luijk, S.J. van, Wagner, C., Bijnen, A.B. Possible solutions for barriers in incident reporting by residents. Journal of Evaluation in Clinical Practice: 2010

12 Scientific Software Development GmbH (2006) Atlas.ti, The Knowledge Workbench, Visual Qualitative Data Analysis, Version 5.2.0, Scientific Software Development GmbH, Berlin.

13 Boeije, H. R. (2005) Analyseren in Kwalitatief Onderzoek: Denken En Doen. [Analysis in Qualitative Research: Thinking and Doing]. Amsterdam: Boom Onderwijs.

14 Ajzen, I. (1991) The theory of planned behavior. Organizational Behavior and Human Decision Processes, 50, 179-211.

15 Millstein, S. G. (1996) Utility of the theories of reasoned action and planned behavior for predicting physician behavior: a prospective analysis. Health Psychology, 15, 398-402.

16 Kaldjian, L. C., Forman-Hoffman, V. L., Jones, E. W., Wu, B. J., Levi, B. H. \& Rosenthal, G. E. (2008) Do faculty and resident physicians discuss their medical errors. Journal of Medical Ethics, 34, 717-722.

17 Schuerer, D. J. E., Nast, P. A., Harris, C. B., Krauss, M. J., Jones, R. M., Boyle, W. A., Buchman, T. G., Coopersmith, C. M., Claiborne Dunagan, W. \& Fraser, V. J. (2006) A new safety event reporting system improves physician reporting in the surgical intensive care unit. Journal of the American College of Surgeons, 202, 881-887.

18 Fukada, H., Imanaka, Y., Hirose, M. \& Hayashida, K. (2010) Impact of system-level activities and reporting design on the number of incident reports for patient safety. Quality and Safety in Health Care, 19, 122-127.

19 Ajzen, I. (2006) Constructing a TPB Questionnaire: Conceptual and Methodological Considerations.

20 Francis, J. J., Eccles, M. P., Johnston, M., Walker, A., Grimshaw, J., Foy, R., Kaner, E. F. S., Smith, L. \& Bonetti, D. (2004) Constructing questionnaires based on the Theory of Planned Behaviour. A manual for health services researchers.

21 Ajzen, I. (2006) Behavioral Interventions Based on the Theory of Planned Behavior.

\section{TABLES AND FIGURES}

\section{Table 1}

Table 1 content of toolc guide

\begin{tabular}{|c|c|}
\hline Openng questions & $\begin{array}{l}\text { Please wilte down what first comes to mind } \\
\text { when you think of barriers to incident } \\
\text { reporting. Read aloud what you have written } \\
\text { down. Items are not yet to be dlscussed. } \\
\text { On a montriy basis, how often do you encounter } \\
\text { an incident? How many incidents are actually } \\
\text { reported? }\end{array}$ \\
\hline Key questions & $\begin{array}{l}\text { What prevents a resident from making a report? } \\
\text { What are the most important barriers mentioned? } \\
\text { How can these barriers be solved? }\end{array}$ \\
\hline Fingl questions & $\begin{array}{l}\text { Are there mportant lssues that we have not } \\
\text { dlscussed? } \\
\text { Do you have any recommendations for the next } \\
\text { focus groups? }\end{array}$ \\
\hline
\end{tabular}

Table 2 
Martowirono, K., Jansma, J.D., Luijk, S.J. van, Wagner, C., Bijnen, A.B. Possible solutions for barriers in incident reporting by residents. Journal of Evaluation in Clinical Practice: 2010

Table 2 Characteristics of the foous group partidpants

\begin{tabular}{|c|c|}
\hline \multicolumn{2}{|l|}{$A g e$ [years] } \\
\hline Range & $25-37$ \\
\hline Medlan age & 30.4 \\
\hline \multicolumn{2}{|l|}{$\operatorname{sex}, n[\%)$} \\
\hline Male & $15(68.2)$ \\
\hline Female & $7(31.8)$ \\
\hline \multicolumn{2}{|l|}{ Trainee, $n(\%)$} \\
\hline Yes & $14(63.6)$ \\
\hline No & $8(36.4)$ \\
\hline \multicolumn{2}{|l|}{ Dlsclollne, $n[\%)$} \\
\hline Cardblogy & 4 [18. 2) \\
\hline Surgery & $4[18.2\rangle$ \\
\hline Orthopsedcs & $2[9.1]$ \\
\hline Blological chemistry & $2[9.1\}$ \\
\hline Radlology & $2[9.1]$ \\
\hline Internal medicine & $2[9.1]$ \\
\hline Emergency care & $1[4.5]$ \\
\hline Hospltal pharmacy & $1[4.5]$ \\
\hline Gerlatrics & $1[4.5]$ \\
\hline Paedlatrics & $1[4.5]$ \\
\hline Pneumonology & $1[4.5]$ \\
\hline Rehabliltation & $1[4.5]$ \\
\hline \multicolumn{2}{|c|}{ Participant in patient safety course, $n(\%)$} \\
\hline Yes & 4 [18. 2) \\
\hline No & $18(81.8)$ \\
\hline
\end{tabular}

Table 3

Table 3 Incident characteristics that lead to underreporting

This incident has no major patient consequences.

This incldent has happened before and has already been reported.

This incident was not preventable.

The cause of tris incident is already clear.

This incident is unlkely to happen again.

This is not an inddent, but a complication.

This incident is aready discussed with the persons irwolved.

\section{Table 4}

\begin{tabular}{|c|c|}
\hline $\begin{array}{l}\text { Solutions to Influence } \\
\text { attitude }\end{array}$ & $\begin{array}{l}\text { Provide the possibility to report anonymously. } \\
\text { Prowde the possibility to report without identifying the persons } \\
\text { Irwolved. } \\
\text { Prowde feedback. } \\
\text { Prowde feedback to the reporter of an hcident on how the report will } \\
\text { be handled. Communicate the results of incident reports in terms of } \\
\text { system changes. }\end{array}$ \\
\hline $\begin{array}{l}\text { Solutions to Influence } \\
\text { culture }\end{array}$ & $\begin{array}{l}\text { Create an incident reporting culture. } \\
\text { Create a culture in which incident reporting is less emotionally } \\
\text { charged, for example by systematicaly discussing indident reporting } \\
\text { within a ward and by a stimulating role of superiors. }\end{array}$ \\
\hline $\begin{array}{l}\text { Solutions to influence } \\
\text { percelved abilty }\end{array}$ & 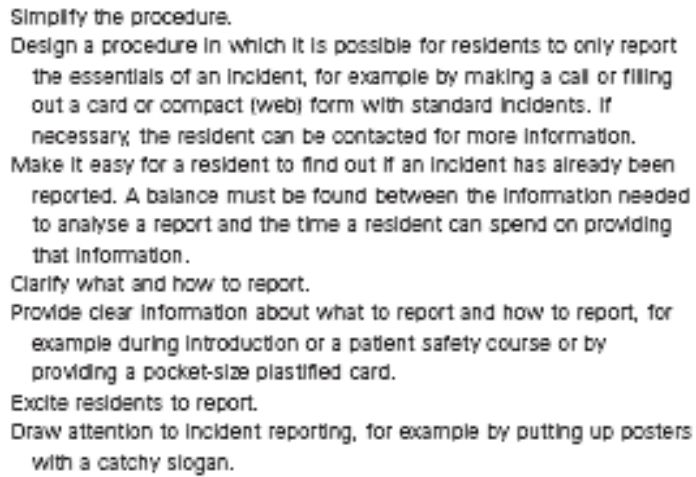 \\
\hline
\end{tabular}


Martowirono, K., Jansma, J.D., Luijk, S.J. van, Wagner, C., Bijnen, A.B. Possible solutions for barriers in incident reporting by residents. Journal of Evaluation in Clinical Practice: 2010

\section{Figure 1}

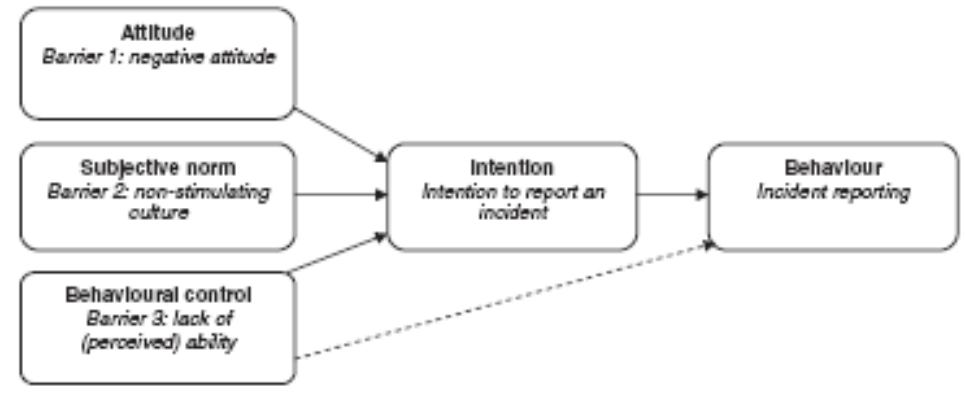

Flgure 1 Relationship tetween the theory of planned behawour and the barriers found in this study. 